\title{
The Strategy of Improvement of the Primary School Children's Creativity based on the Ukrainian Question Research
}

\author{
Tetiana VANKHALSKA \\ Master's Graduate Program in Pedagogy \\ Jiangsu University - P.R. \\ China
}

\begin{abstract}
In this article the main goal was to analyze modern approaches to the theoretical study and practical study of creativity, find out the main factors influencing the increase of the level of creativity of primary school children based on the Ukrainian question research, to visualize this qualitative analysis of the data collected and processed in the process of practical survey, testing, analysis works on the basis of the test of John Renzulli. This paper presents the results of the interpretation study of two primary schools in Ukraine. Research question that are supporting and enhancing creativity of elementary school students.
\end{abstract}

Keywords: pedagogy of creativity, creative skills, John Renzulli ring, Torrance

\section{Introduction}

The relevance of the Concept of creativity has always attracted the attention of psychologists, educators, art historians, and philosophers. It has lost its importance today, allowing to put all new questions to scientists and to find optimal ways for its development and formation. The development of personal achievements in life is closely connected with such individual psychological characteristics of the person. Such as ability and talent. We know two things about intelligence:

- It's diverse. We think about the world in all the ways that we experience it. We think visually, we think in sound, we think kinesthetically. We think in abstract terms, we think in movement.

- Intelligence is dynamic. If we look at the interactions of a human brain, intelligence is wonderfully interactive. We all create our own lives through this restless process of imagining alternatives and possibilities, and one of the roles of education is to awaken and develop these powers of creativity. Instead of a culture of standardization that is dominate now.

Creativity gives the opportunity to develop strength of character, which must be resistant. Strength of character becomes an integral part of our future, day by day - not week, not month, and for many years of hard work dedicated to making the future a reality. Therefore, the role of education is most important. The study of historical context on the development of creativity has allowed to establish that the first mention of the term "creativity" in scientific publications relates to the beginning of the 20th century. Long famous biographical study of creative abilities and talent, L. M. Termen and K. Cox (1921, 1926), the idea of H. Wallace (1926) on the stages of the creative process. "The pioneer of the psychology of creativity" (50 years of the 20th century) called the George. Guildford, who proposed to differentiate between convergent and divergent (creative) thinking. 60-70-ies of the 20th century a remarkable increase in the number of publications on the issue of creativity. For example, the work of E.P.Torrance, J.Getzels and R.Jackson, testifying to the lack of correlation between indicators of intelligence and creativity; multimodal concept (R. Sternberg, J.Renzulli, K.Heller) and many others. In the post-Soviet and Soviet pedagogy, the scientific study of intelligence, abilities (mental, creative, talent) also have deep roots (D.B.Bogoyavlenskaya, A.V.Zaporozhets, L.A.Venger, L.S.Vygotsky, V.A.Krutetskiy, N.With.Leites, S.L.Rubinstein, B.M.Warm and other famous scientists). In 1975 was created The World Council for Gifted and Talented Children, Inc. (WCGTC) is a worldwide non-profit organization that provides advocacy and support for gifted children. The WCGTC is a diverse organization networking the globe with an active membership of educators, scholars, researchers, parents, and others interested in the development and education of gifted and talented children of all ages. 
The WCGTC consists of its Members, Executive Committee, Delegates from member countries, and a Headquarters that recently relocated to Western Kentucky University in Bowling Green, Kentucky. The existence of such organizations is clearly proves the relevance of this issue in world education. Especially in the field of education of children in primary school, where the Foundation is laid for further development of creativity and transform the experience of creative activity as an important source of personal growth and self-development. In addition, despite the long-term, sustained interest in certain problems, a number of scientific aspects of the problem of creativity remains relevant because of the ambiguous, poorly known, or insufficient amount of data presented. Among them - the category of "creativity" in the field of creativity, the context of "creativity" in General and "the development of creativity of younger students in the pedagogical process" are in particular.

As mentioned above, primary school age is the most sensitive for the development of creativity, as in this period the formation of bad habits begins with the lack of creative training, which largely effects on success/failure of an adult. However, the relevance of the topic reveals the contradictions of public and private order.

The object of study: the pedagogical process (in primary school).

Subject of research: the development of creativity of children in primary school in the pedagogical process.

\section{The hypothesis of the study:}

In the development of creativity of younger school students it is possible to achieve positive results if:

- Argued and applied a set of conditions, including the features of development and self-development subjects; purposeful pedagogical activity (pedagogical interaction as creative freedom, safe creative space and creative teacher), the creative properties of the environment;

- Justified, developed, and introduced into the pedagogical process of effective model development, with emphasis on the areas current status.

- Defined criteria, levels of development of creativity, assessment of creativity index of each child., performed diagnostic and research complex to identify creativity,

- Developing a program that contains a variety of curricular and extracurricular forms of organization of creative activities;

\section{To achieve this goal and test the hypothesis for the following objectives:}

- To analyze modern approaches to the theoretical study and practical study of creativity

- Study on foreign data and on the basis of Ukrainian studies, the retrospective, current status, identifying key approaches to the study of creativity in context of development of primary school pupils.

- To formulate the theoretical principles of the methods of development of creativity of younger school students.

\section{Research methods:}

Theoretical methods: studying scientific literature. Theoretical analysis.

- Empirical methods: discussion, questioning, testing, method of expert evaluation, content analysis and qualitative analysis of texts, creations, different kinds of observations.

- Empirical framework and main stages of study: Conducted analysis of domestic and foreign publications to improve creativity and value of creativity, children's educational and methodological literature. Studied innovative experience in the practice of the Kharkov schools, the selected experimental and control classes. The experimental sample consisted of 4 classrooms (81): school № 122; and school № 145. Conducted surveys, testing and conversation with students. The final stage was carried out comparative analysis of the obtained data was interpreted and reasoned results, conclusions.

\section{Scientific novelty of the research:}

Identified and justified the place of the concept of "creativity" in the field category of "creativity" in the context of the hierarchical structure of its derivatives. The phenomenon of creativity convincingly in a broad sense, as in the ascent from stimulant-productive role model for creative self-revelation of personality. In a narrow sense, creativity as a general ability to creativity is manifested in the 1) process; 2) the product of the creative process; 3 ) characteristics, properties of the personality (as supplies creative personality type). Synthesis of selected components forms a triad, which reflects the holistic phenomenon of creativity.

2.The Problems on the Development of Creativity of Younger Students in the Modern Educational Environment 
One of the major problems today, blocking the development of creative thinking students, is to strengthen the system of testing in schools. This largely simplifies the work of teachers and streamlines the process of validating the level of knowledge, but in the global aspect carries a defective effect on the thinking of the child. The dominant culture of education has come to focus on not teaching and learning, but testing. Now, testing is important. Standardized tests have a place. However, testing system should support learning. It shouldn't obstruct it. So in place of curiosity, what we have is a culture of compliance. Children and teachers are encouraged to follow routine algorithms rather than to excite that power of imagination and curiosity. The second factor is the productivity of the workflow. Creating an unfavorable environment for the assimilation of material by students. The study of cognitive psychologist Ronald T. Kellogg, who decided to find out how schedules, daily rituals, and work environment affect creativity. Kellogg writes: "There is evidence that the environment, the daily routine and ritual (habitual) actions could stimulate and increase its efficiency, enhance focus and reduce the entropy level of attention. These factors can cause a state of flux, and not, as used to consider, boredom or anxiety. Room, time of day, or ritual prior to the work, can stimulate concentration, to increase motivation or to arouse a certain emotional state. In addition, each of these aspects the method is able to awaken in your mind specific ideas, facts, plans that you associate with the place, time, visual representation and other things somehow related to your chosen theme and work."

Kellogg has formulated some very important findings that can affect our productivity. For example, he found that background noise, paradoxical as it may sound, can have a positive impact on creativity. For example, while the noise of high intensity (more than 95 decibels) is destructive for the complex tasks it contributes to maintaining concentration when performing repetitive work and boring task, lacking creativity. Such noise usually increases the level of excitation, which may be useful when fading attention during mindless and monotonous action, but detrimental to the flow and deep immersion in work that requires clear thinking. Of course, Kellogg makes a nod to the individual peculiarities of the psyche and recognizes that for anxious individuals, noisy environment is confusing. In the end, the scientist says that everyone needs to determine a comfortable level of background noise contributing to the conservation of flow. Another factor that drew the attention of the Kellogg on one working session is that, he points to a number of studies, according to which the work lasting from 1 to 3 hours with small breaks. "In addition, the study of circadian rhythms (cyclical fluctuations of the intensity of various biological processes associated with the change of day and night) confirm that working on complex, creative tasks are the most effective in the morning".

Abstract ideas, images, plans, suggestions, emotions, and other personal symbols that represent the knowledge necessary for creative work, are associated with the environment, namely time and place that the student uses to work. These associations are fixed, if students are using the selected environment for specific activities. The entrance in this environment becomes a kind of symbol search, which is able to activate all of the information stored in the subconscious. After he concentrates on coming from own subconscious ideas, the workflow captures it completely. So the specific characteristics of the environment can be defined prompts for reflection, searching and creativity.

Our education system is predicated on the idea of academic ability. And there's a reason. Around the world, there were no public systems of education, before the 19th century. They all came into being to meet the needs of industrialism. So the hierarchy is rooted on two ideas:

- That the most useful subjects for work are at the top. So most part of children probably steered benignly away from things at school, things they like, on the grounds that they would never get a job doing that. Isn't that right? Don't do music, you're not going to be a musician; don't do art, you won't be an artist. The whole world is engulfed in a revolution.

- The academic ability, which has really come to dominate our view of intelligence, because the universities designed the system in their image. The whole system of public education around the world is a protracted process of university entrance. And the consequence is that many highly-talented, brilliant, creative students think they're not, because the thing they were good at school wasn't valued, or was actually stigmatized.

In the next 30 years, according to UNESCO, more people worldwide will be graduating through education than since the beginning of history. More people and it's the combination of all the things - technology and its transformation effect on work, and demography and the huge explosion in population. Another equally important issue is facing the education system today. "Technologically expanded consciousness" This question has a lot of both positive and negative sides. 
This process of mixing our minds and devices compels us to take stock of who we are and who we want to be. Consider the issue of independence is perhaps the most cherished of the rights that we have inherited from the Enlightenment. The word means self-government and refers to our ability to make decisions for themselves and for themselves. The results of the meta-analysis of data with magnetic resonance imaging of the human brain. The result of the brain mapping by MRI while the subjects viewing the given paintings, scientists have found that this process causes activity in areas of the brain associated with "vision, pleasure, memory, recognition and emotions, in addition to the departments that are responsible for conscious processing of new information, assigning it a meaning". That is, when we look at a piece of paper with some inscriptions or any other material object, we just process information and classify what we saw, but while viewing the work of artists or photographers, our neurons play a show created from fleeting memories, unexpected imagery and emotion. («Neural correlates of viewing paintings: evidence from a quantitative meta-analysis of functional magnetic resonance imaging data», NCBI.)

During their research, Professor Dweck came to the conclusion that there are two kinds of people: some consider intelligence as a fixed quality (such say to themselves "I am, and therefore it is that I can") - Dweck calls the representatives of the entity models; others, representatives of the incremental model, according to Dweck, are convinced that intelligence is something changing. This implies all the consequences: people who believe that at a certain age learning is not able to take them to the limit of their capabilities, and don't put extra effort to achieve goals, while proponents of incremental theories view their potential as unlimited, strive to acquire new skills and succeed. What determines this division, Dweck does not know, but she is convinced that the experience of people who continue to improve their skills, and by constantly achieve new goals, suggests that there are no limitations except those we ourselves invented. Based on the foregoing, identifying the problem of further investigation: how to promote the development of creativity of younger students in the pedagogical process? Was conducted comparative analysis of the problems, which became the theoretical resource for creative solutions? At the moment there is conceptual types and preconditions for the study of problems of development of creativity of younger school students on the basis of Ukrainian studies. The search for explanations of the nature of creativity, the essence of the values of creativity, talent contributed to the emergence of basic concepts and the establishment of scientific schools.

\section{Basic Modern Concepts of Creativity}

One of the original and relevant modern concepts about creative thinking are the works of Angela Duckworth. She came to the conclusion that an IQ is not the main indicator of the success of students. In all different situations one character trait was a definite success. And it's not social skills, not external beauty or health, and even IQ. It was strength of character which formed with the knowledge of the child of his individuality and originality of thinking. Same concept we can see in the book "How children succeed" of Paul Tough. He says the following on the work of Duckworth: "She considers it appropriate to divide the mechanics of achievement goals on two separate dimensions: motivation and will. Each of them, she says, is necessary to achieve long-term goals, but not self-sufficient. Most of us have the motivation, but no will: you can be extremely motivated to lose weight, but if you do not have enough will and self-control to abandon the familiar, you are unlikely to succeed. If the child has enough motivation, then you need to think about how to develop strength of character. What if a person has no motivation in achieving the goal? Then any self-control and such tricks will have no effect."

Also famous model is The Snowflake Model of Creativity-differentiating creative people from others using David Perkins' Six-Trait Model. The model consists of the following elements:

- A strong commitment to a personal aesthetic. Creators have a high tolerance for complexity, disorganization, and asymmetry. They enjoy the challenge of struggling through chaos and struggling toward a resolution and synthesis.

- The ability to excel in finding problems. Scientists value good questions because they lead to discoveries and creative solutions, to good answers.

- Mental mobility allows creative people to find new perspectives on and approaches to problems. Creative people have a strong tendency to think in opposites or contraries. They often think in metaphors and analogies and challenge assumptions as a matter of course.

- A willingness to take risks and the ability to accept failure as part of the creative quest. These people also exhibit the ability to learn from their failures. By working at the edge of their competence, where the possibility of failure lurks, mental risk-takers are more likely to produce creative results. 
- Creative people not only scrutinize and judge their ideas or projects, they also seek criticism. Objectivity involves more than luck or talent; it means putting aside your ego, seeking advice from trusted colleagues, testing and retesting your ideas. Personal objectivity and self-reflective behaviors, especially about work or creations, are very hard to carry off well and require folks to distance themselves and then look at themselves and their creations for a distance. Objectivity is something very hard to achieve.

- Creators are involved in an enterprise for its own sake, not for school grades or paychecks. Their catalysts are the enjoyment, satisfaction, and the challenge inherent in the work itself.

Another variant of creative model is Brainstorming by WilferdArlan Peterson. "Brainstorming is an existing process by which individuals strive to stimulate and inspire each other to create ideas. The purpose is to tap the subconscious mind of each member in a group and create a mutual sharing of mental wealth of those participating. Through the mechanism of association, one idea will suggest another and another . . creating a chain reaction.".

Among the numerous contemporary studies on the basis of Ukrainian study - a great reputation has also become fundamental work of post-Soviet researchers such as V.N.Druzhinin (psychology of General abilities and creativity).WithD.B.Bogoyavlenskaya (the concept of giftedness, the method "Creative field"), A. I.Savenkova (the theoretical model of the development of children's giftedness in the educational environment in the context of an integrative approach). At the same time search for new innovative solutions leads to the emergence of various modifications, and adapted copyright procedures, for example: analysis of the ways to complete the picture (O.Dyachenko, A.I.Kirillov), "Completion of images" (adaptation of V.N.Druzhinina), the use of games as research models (B.S.Ermakova, V.N.Druzhinin and N.I.Gasratova, M.S.Semiletkin); General pedagogical diagnostics of gifted younger students A.I.Savenkova, creative tests E.E.Tunick, etc.

According to modern writers, the traditional elementary school does not provide the optimum level of development of creativity and creative abilities. This, presumably, depends on the harmonization of curriculum, textbooks, approaches, forms and methods of organization of training and education, as well as the level of creativity of the teacher. The underdevelopment of this problem in theoretical and practical plan defined the overall goal of our research, which consisted in theoretical and empirical justification of the model, the conditions of the program of development of creativity of younger schoolboys in the pedagogical process. The priority was to highlight the problem in the minds of teachers, parents, and the development in children of intrinsic motivation for creativity as dominant.

\section{The Theoretical Significance of the Research}

Formulated and argued substantive theoretical basis for the development of creativity as a general (primary, universal, independent) creativity with focus on the child's motivation to self-development, potentially important for the theory of pedagogy of primary school. Disclosed and systematized the main approaches to the problem of creativity in domestic and foreign science, emphasized the context of "development" (development area creativity, levels, etc.), the obtained data have made the theoretical basis for the empirical research. Allocate an independent type of creativity: personality and behavior (V.N.Druzhinin), intellectual, and behavioral (I.A.Sleepgova), verbal, visual (nonverbal), word-sound (E.P.Torrance), "specialized" creativity — the ability to work in a particular sphere of human activity (literature, music, science, etc.), which develops on the basis of overall creativity. Sometimes use division on the basis of age: early and late creativity. From which we can conclude that creativity cannot exist only as a theoretical construct. Hence, justified derived from the term creativity (creative personality, creative behavior, creative thinking, as well as creative product and the result).

In the theoretical modeling of the process of development of creativity of younger school students, we relied on the well-known concept of JohnRenzulli, which is actively used for the development of educational models in the context of creativity and talent. The main argument: creativity is one of the most important characteristics of giftedness (D.B.Bogoyavlenskaya, V.N.Druzhinin, JohnRenzulli, etc.). As a result, the structure of creativity is presented as a triad:

- Creative orientation of the personality (the motivation of creativity as a dominant, demand);

- Creative (productive) thinking;

- Special abilities. 
This approach allowed us to formulate a working definition of creativity. This component of the model-triad ensures the success of students, this includes children with a medium level of development of abilities, and plays, according to the research of L.V.Svetlichnaya, a compensatory function. This combination of the special abilities of the individual in their "favorable combination" allows the child to navigate in the creative task, and successfully carry out the creative activity, showing autonomy and non-stimulated (creative) activity, imagination, fantasy, the desire to go beyond the given problem. Therefore, we apply the idea of "rings JohnRenzulli" allows you to focus on the equivalence of the components of the triad (Fig. 1).

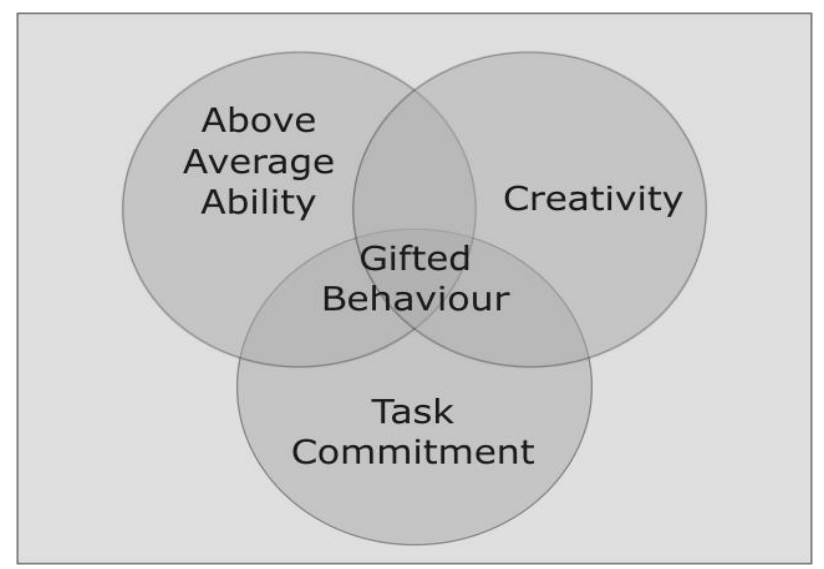

Figure1. The model of the creativity development

As you can see from the image, the "ring of creativity" has a projection on the space zones of the current status of creativity, the inner development and self-development. Thus, the development of the outlined as the promotion of the child by assigning a creative experience in collaboration with adults and peers; "The journey to the future development." Overall, the pedagogical process in the broadest context of this study, we consider as the most general, integrative condition for the development of creativity. Each student included in this objectively existing pedagogical reality. However, it is logical to allocate a variable component of the conditions and carry out the differentiation. We emphasize that the conditions can be categorized as pedagogical, if you intentionally and knowingly are included in the pedagogical process, are taken into account in the organization of pedagogical interaction. (See the model in Fig. 2).

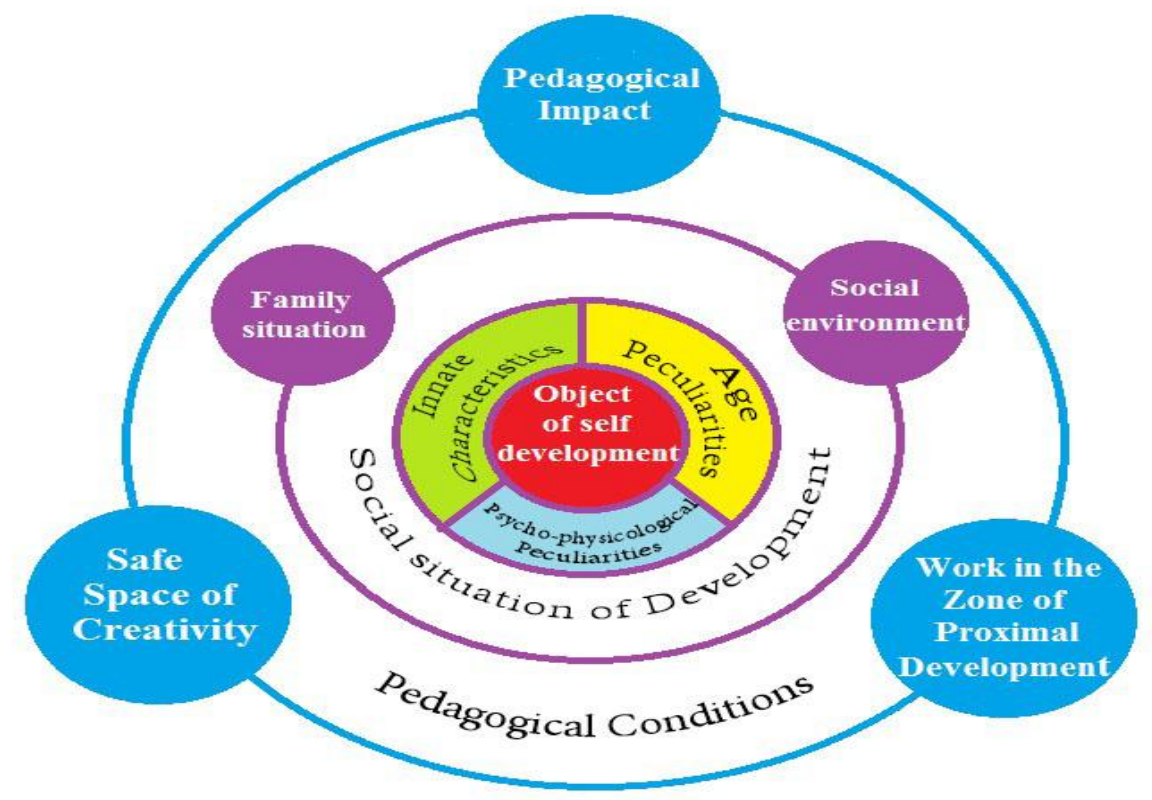

Figure 2. The Model of the conditions of development of the primary school children`s creativity. 
The first group of terms connected with the subject of development and self-development: a child, his features. In the structure of this group of conditions, select the following components.

- Physiological features. The most active period of intensive formation of physiological and mental functions is childhood. Visual, auditory and kinesthetic systems evolve unevenly in the child that determines the ways of perception, memorizing and reproduction. As individual representations of the world, in order to efficiently implement all types of communication (including creative) should take into account differences in the development of representative systems using leading modality and to enhance the abilities of each child, developing other representational system (Bandler R., Grinder D.).

- Innate characteristics have a significant impact on the development process, and to a large extent determine the contours of future developments. Of course, special educational technology can correct many, but not all, stressed A.I.Savenkov. In the real process of creativity is difficult to separate the influence of social and natural factors. The Age-related features and related sensitive periods in the development of various types of creativity an important pedagogical condition. A Premature or delayed educational interventions are not effective enough and adversely affects the development of personality (A.I.Savenkov).

The second group of conditions determines the pedagogical activity. First, the focus is on developing creativity, the organization of pedagogical space (psychological and physical) and in accordance with the purposes of creative development of children. Second, substantive and technological infrastructure (programs, methods, tools, forms, procedures aimed at diagnosis and the development of creativity). Both directions are provided by the following pedagogical conditions:

- Organization of pedagogical interaction as a freedom of creativity (creation of positive examples of creative thinking, behavior, relationships; creativity teachers; adoption and reinforcement of creative behavior). In this context highlight specific conditions:

- The inclusion of a child in an interesting activity;

- Create ad-hoc situations;

- Transformation of creative tasks taking into account the zone of proximal development.

The work of the teacher in the zone of proximal development of child's creativity (educational efforts aimed at identifying the level of creativity, motivating creative self-development, promotion in the zone of proximal development and creative self-development).

- The organization of a creative space (the material conditions for creative activities, trusting relationships in the classroom, positive expectations, creating situations of success; etc.).

The third group of terms reflects the social and family situation, i.e. the influence of the environment on the development of creativity of the child. Pedagogical context of this group of conditions argues for the following position. Social situation of development has a two-level character: base, which defines the main content of development and the level of incremental changes, the accumulation of which leads to a transformation of baselevel and overall (L.S.Vygotsky). For the development of children's creativity is the importance of social reinforcement of creative behavior of the child; the expectations of parents (expectations of achievement, success, positive parent early programming). One of the main objectives of this study were to establish a precedent of acquisition of creative experience, as well as to simulate on the practice of pedagogical conditions conducive to the expression and development of creativity of each student as an individual.

In this study were used the conceptual idea of "enriching model" of John Renzulli, intended for the education of gifted students in the regular school. The main forms of development of creativity of the program include lessons creative direction. Used art-therapeutic games and exercises (according to the method of L.D.Lebedeva); adapted to the Junior school age exercises from the training, acting games, improvisation and role play; theatrical; inventing and illustrating stories, fairy tales, etc. Enrichment creative space was achieved using a variety of objects, the possibility of transformation and variability of application. Thus, it was introduced a number of restrictions on aggressive expression of emotions and feelings; on the comparative and evaluating judgments, negative evaluations, grades, criticism, punishment. It was noted that creating a positive emotional background significantly increases the dynamics of development of creativity of children.

Through the content analysis stood out sensory predicates were counted and their number for each test separately. Just tested 81 student: 35 people (43.2 per cent) is a leading kinesthetic modality; in 29 cases ( 35.8 percent) is the leading visual modality; in 11 patients $(13,6 \%)$, the leading auditory modality; in $6(7,4 \%)$, the polytonality. 
Also used: short version of the Torrance test - verbal part ("Figure form"); diagnostics the flexibility of constructing a graphic image (a modified version of the test Torrence). Emphasis on the diagnosis of non-verbal creativity logical because of the peculiarities of children's age as the youngest function of the psyche - it is only being formed, a natural "language" for Junior pupils is a drawing - a kind of graphic counterpart of speech (L.S.Vygotsky).

The final criterion for selected levels of development of creativity of younger school students, operational criteria is the difference between the values of the studied characteristics for the period of the pilot study. It is highlighted that three main levels available for observation, and two transitional levels of proximal development of creativity. They reflect different status of the investigated characteristics when theyreaches the next level, but higher than that of the previous one.

The level of potential creativity(low) is characterized by the manifestation of individual creative properties under the influence of any external stimulus. In children with the level of potential ("primary") creativity, originality product of creative activity (drawing, stories, crafts) acts as an end in itself, a manifestation of originality is random. The value of creative products and activities are low, the total index of creativity Ic(average value) range: 0,00 - 0,2. Creativity OK: 31-21 score (and below). The value of the transitional level 1 of proximal development: Ic(average value) 0,21 - 0,3. The total value of creativity in the interval OK: $42-32$ points.

The level of situational creativity (average) is characterized by instability of creativity. Children at this level are distinguished creative activities interest in creative activities, however the measure of their severity is largely determined by the situation, the presence of creative samples. Each creative product is evaluated and experienced by the child as discovery, creative discovery, and event. Overall, the value of creative products and activities the average, the total index of creativity Ic (average value) in the range 0,31-0,5. Creativity OK: $63-43$ points. The value of the transitional level 2 of proximal development: Ic(average value) 0,51-0,69; OK: 84 - 64 points.

The level of active creativity (high) sustainable manifestations of creativity, consistently high values of the indicators of all components of creativity, as creative process and product. Independent, not stimulated from the outside the problem statement qualitative feature of the children of this level. In the activities dominated by internal motivation, the child is motivated towards self-actualization in creative activity, shows a tendency to various types of self-education and creativity. Overall, the value of creative products and activities is high, the total creativity index Ic (average value) in the range of $0.7-1,00$. The total value of creativity in the interval: 105-85 points.

Table1.

\begin{tabular}{|l|l|l|l|l|l|l|l|l|l|l|l|l|l|l|}
\hline Levels & $\begin{array}{l}\text { The } \\
\text { Number } \\
\text { Of } \\
\text { People }\end{array}$ & $\%$ & $\begin{array}{l}\text { Ic } \\
\text { average }\end{array}$ & $\begin{array}{l}\text { The } \\
\text { Number } \\
\text { Of } \\
\text { People }\end{array}$ & $\%$ & $\begin{array}{l}\text { Ic } \\
\text { average }\end{array}$ & $\begin{array}{l}\text { The } \\
\text { Number } \\
\text { Of } \\
\text { People }\end{array}$ & $\%$ & $\begin{array}{l}\text { Ic } \\
\text { average }\end{array}$ & OK & $\begin{array}{l}\text { The } \\
\text { Number } \\
\text { Of } \\
\text { People }\end{array}$ & $\%$ & $\begin{array}{l}\text { Ic } \\
\text { average }\end{array}$ & OK \\
\hline E & E & E & C & C & C & E & E & E & E & C & C & C & C \\
\hline LPD1 & 9 & 0,0 & - & 0 & 0,0 & - & 15 & 18,5 & 0,92 & 99 & 3 & 3,4 & 0,81 & 85 \\
\hline Average & 15 & 11,1 & 0,65 & 11 & 12,6 & 0,61 & 17 & 21,0 & 0,81 & 84 & 12 & 14,0 & 0,66 & 67 \\
\hline LPD2 & 19 & 23,5 & 0,39 & 17 & 19,6 & 0,41 & 29 & 35,8 & 0,69 & 62 & 24 & 27,6 & 0,49 & 44 \\
\hline Low & 38 & 46,9 & 0,11 & 22 & 25,3 & 0,19 & 16 & 19,8 & 0,27 & 41 & 27 & 31,0 & 0,27 & 32 \\
\hline
\end{tabular}

\section{Beginning of experiment End of experiment}

E- experimental sample (81 people)

C-Control sample (87 people)

LPD1 - level 1 of proximal development

LPD2 - level 1 of proximal development

Ic - index of creativity

Graphical data distribution of participants by selected levels of creativity presented on the final chart.

Number of Participants in \% 


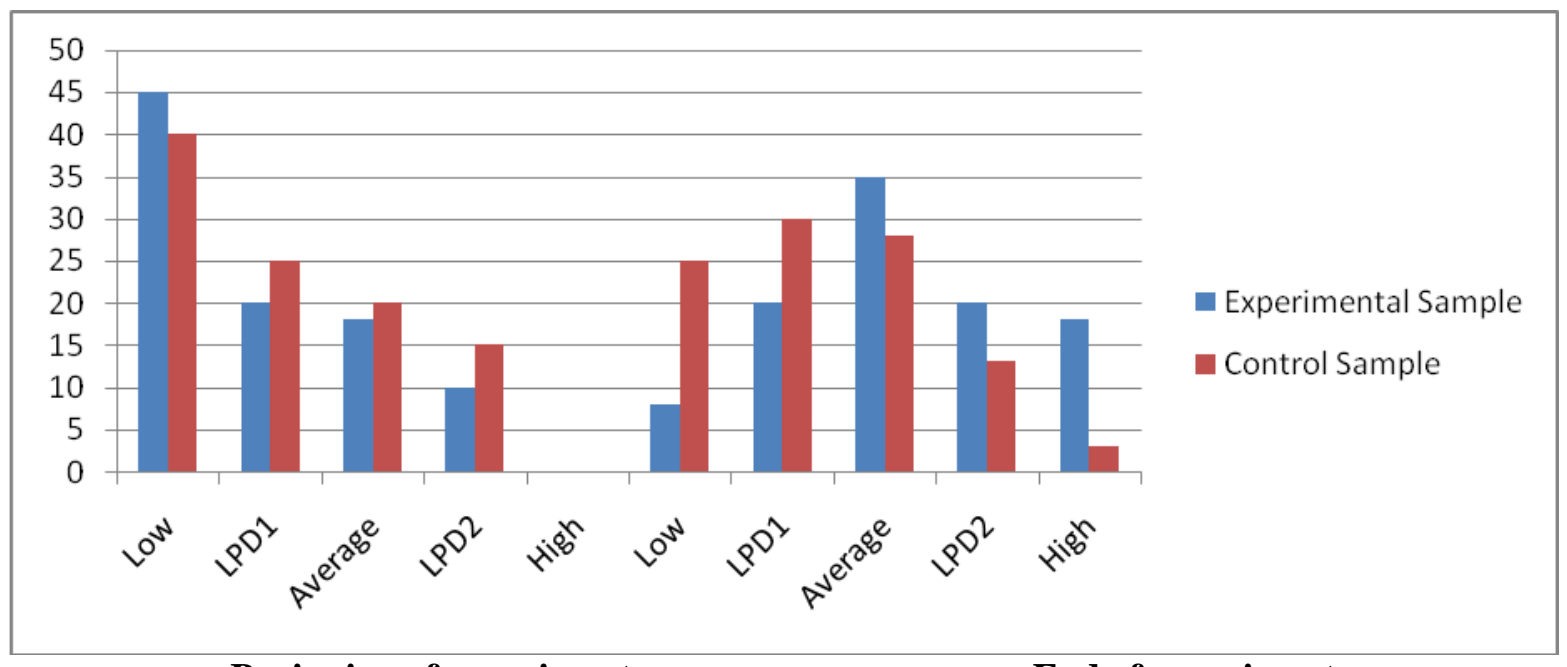

\section{Beginning of experiment \\ End of experiment \\ Fig. 3. The levels of development of creativity of younger school students}

As can be seen from the tables and histograms, the upward trend of the level of creativity expressed in the experimental sample and the control sample, the changes are less significant.

Definitely, obtained good results in the experimental group accompanied by the effect of the complex impact of various factors; including natural processes of personality development. However, recorded a positive trend, significantly exceeding the dynamics of creativity in the control classes, is a sufficient basis for a conclusion about the effectiveness of increasing the creativity of younger school students.

\section{Conclusion}

A study of creativity of younger school students reflects the current situation of the reform of primary education. It is obvious that the satisfaction of social demand for a creative person, able to adapt flexibly to a rapidly changing environment, emphasizes both theoretical and applied aspects of the problem, starting with the period of childhood. Priority creative component in the overall structure of a child's personality determined the direction of changes the nature of pedagogical process in primary school. A complete person is always a person of creativity, developing, characterized by the manifestation of the all-new psychological tumors and reconstruction of already existing structures. The result of this work, it is possible to make following conclusions:

- The historical context of the studied phenomenon illustrates the peaks and valleys of research interest in the problems of creativity in the scientific community. The lack of reliable stable connection between intelligence and creativity contributed to the separation of research creativity as a distinct phenomenon in subject area creativity (creative thinking, etc.). The most controversial remain issues of identification and measurement of creativity.

- In this study creativity is seen:

- In a broad sense as an independent phenomenon, manifestations of which can be observed in the creative process; the result (the product of the creative process); the characteristics (properties) of the individual as supplies creative personality type;

- In narrow sense - the overall creativity potentially inherent in each child.

- In the simulation of the development of creativity of younger school students the main support for the collection of this was punctuated by the concept of giftedness by Renzulli, on the grounds that creativity is seen as a component of giftedness. Applied the idea of "John Renzulli rings" allows you to focus on the equivalence of components in the model structure.

- Effective implementation of creativity development in practice is determined by the set of conditions contributing to appearance and development of the overall creativity of each student in his characteristic pace consistent personality.

- Differentiated levels (core and levels of proximal development of creativity as transient), defined the corresponding metrics and criteria to reflect a collective picture of positive change. There were statistically significant correlation between the leading representational system primary school children and the development of his creativity. 
- Among the established scientific concepts and modern theories as the methodological basis for the organization of the educational process is the most justified theory generated abilities. The question of creativity in the pedagogical plan has an age aspect (proven overall ability to creativity develops in children up to 6-7 years under the influence of favorable environmental factors). Therefore, the development of creativity is the teaching guide in the teacher`s job.

We believe that further studies of this phenomenon, its integration with advanced pedagogical concepts will lead to the creation of a holistic, humanistic methodology that will contribute to the harmonious development and creative self-realization of each child.

\section{References}

https://www.world-gifted.org/

http://enrichmenttriadmodel.weebly.com/what-is-triad.html

Angela Duckworth Grit: The Power of Passion and Perseverance,2016, Scribner, 352p.

A.I.Savenkov, Children's giftedness: the development by means of art. 1999 -M.: Pedagogical society of Russia, $220 \mathrm{p}$.

Amabile, T. M. 1983. Social psychology of creativity: A componential conceptualization. Journal of Personality and Social Psychology, 45, 997-1013.

Amabile, T. M. 1988. A model of creativity and innovation in organizations. In B. M. Staw\& L. L. Cummings (Eds.), Research in organizational behavior, Vol. 10, 123-167. Greenwich, CT: JAI Press.

Amabile, T. M. \& Mueller, J. S. 2008. Studying creativity, its processes, and its antecedents: An exploration of the componential theory of creativity. In J. Zhou \& C. E. Shalley (Eds.), Handbook of Organizational Creativity, 33-64. New York: Lawrence Erlbaum.

Bagnall, J \&Koberg, D. The Universal Traveler : A Soft-Systems Guide to Creativity, Problem-Solving, \& the Process of Reaching Goals

Barron Frank,1969, The Creative Person and the Creative Procees. New York,311 p.

Bancroft, S., Fawcett, M., and Hay, P. 2008. Researching children researching the world. Stoke-on-Trent: Trentham Books

Boden, M.A. 2004. The creative mind, 2nd Ed London: Routledge

D. B. Bogoyavlenskaya, 2003, Intellectual activity as a creativity problem. Rostov, $173 \mathrm{p}$.

Chappell, K., \& Craft, A. 2011. "Creative learning conversations: Producing living dialogic spaces?” Educational Research, 53(3): 363-385.

Craft, A. 2000. Creativity across the primary curriculum. London: Routledge.

Craft, A. 2001. "Little c creativity". In A. Craft, B. Jeffrey, and M. Leibling, (Eds.). Creativity in education. London: Continuum.

Cremin, T., Burnard, P. and Craft, A. 2006. "Pedagogy and possibility thinking in the early years". .Journal of Thinking Skills and Creativity 1(2): 108-119

Csikszentmihalyi, M. Flow: The psychology of optimal experience. New York: HarperCollins.

Csikszentmihalyi, M. The evolving self. New York: Harper Perennial.

Csikzentmihalyi, M. Creativity: Flow and the psychology of discovery and invention. New York: Harper Perennial.

Davies D., Jindal-Snape D., Collier C., Digb R., Hay P., Howe A. 2012. "Creative environments for learning in schools". Thinking Skills and Creativity.

David Perkins ,The Snowflake Model of Creativity,http://www.math.harvard.edu/ knill/creativity/snowflake.html V. N. Druzhinin 1995,Psychology of General abilities,Moscow, 230p.

Dul, J., Ceylon, C., \& Jaspers, F., 2011. Knowledge workers' creativity and the role of the physical work environment. Human Resource Management, 50 (6), 715-734

Gelb, M.J. How to think like Leonardo da Vinci, 2000, Reissue edition,336p.

Glass D. Statistical methods in pedagogy and psychology,1976, George. Stanley,. - 495

Golden, B. Unlock Your Creative Genius,Prometheus books, 297p.

Goleman, Kaufman, and Ray,1998, The Creative Spirit, Psychology,185p.

Kellog R. Children's Drawing/Children's Minds,1979. New York: Avon Publishers,-277 p. 
I.A.Sapogova,1993, The modeling procedure as a condition of development of imagination, Questions of psychology. - No. 3. 24-32p.

L.D.Lebedeva, 2012,A comprehensive approach to the problem of diagnosis of gifted children/ journal of the practical psychologist №8.

L. S, Vygotsky,2015, Imagination and creativity in childhood. -M.-93 p.

Marks-Tarlow. Creativity - inside out: learning through multiple intelligences, 1999, Dale Seymour Publications,193p.

Paul Tough How children succeed, 2012, Houghton Mifflin Harcourt, 256p.

Piirto, J. Understanding those who create, 1992, Ohio Psychology Press, 360p.

Piitro, J. Understanding creativity, 2004, Scottsdale, AZ: Great Potential Press,287p.

Robinson, K. Out of minds: Learning to be creative, 2011, Capstone, 2 edition, 352p.

Robinson, K. and Aronica, L. Creative Schools: The Grassroots Revolution That's Transforming Education, 2015, Viking, 320p.

Torrance E.P. Guiding creative talent - Englewood Cliffs, W.J.: Prentice- foll, 1964.-234p.

Shelley Carson, Your creative brain, 2010, Harvard University, 384p.

WilferdArlan Peterson, The art of creating thinking, 1991

Schmier, Louis Atwood, 2002, Publishing Random Thoughts: The Humanity of Teaching.-192p.

Starko, A.J. Creativity in the classroom: schools of curious delight

Sternberg, R.J. \& Williams, W.M. How to develop student creativity 